\title{
Effects of Deposition Potentials on the Morphology and Structure of Iron-Based Films on Carbon Steel Substrate in an Alkaline Solution
}

\author{
Soon-Hyeok Jeon, Geun-Dong Song, and Do Haeng Hur \\ Nuclear Materials Safety Research Division, Korea Atomic Energy Research Institute, 989-111 Daedeok-daero, \\ Yuseong-gu, Daejeon 305-353, Republic of Korea \\ Correspondence should be addressed to Do Haeng Hur; dhhur@kaeri.re.kr
}

Received 17 September 2015; Revised 21 December 2015; Accepted 24 December 2015

Academic Editor: Daniel Guay

Copyright (C) 2016 Soon-Hyeok Jeon et al. This is an open access article distributed under the Creative Commons Attribution License, which permits unrestricted use, distribution, and reproduction in any medium, provided the original work is properly cited.

\begin{abstract}
The purpose of this work is to investigate the effect of electrochemical deposition potential on the morphology and structure of iron-based films on the carbon steel in an alkaline Fe(III)-triethanolamine solution. The deposition potentials were controlled in the range from -1.05 to $-1.23 \mathrm{~V}_{\mathrm{SCE}}$ for $1800 \mathrm{~s}$ at $80^{\circ} \mathrm{C}$. Total amount of electric charge for electrodeposition process was increased with increasing deposition potential in negative direction. Pure magnetite films with a columnar and defect-free structure were deposited in the potential range from $-1.05 \mathrm{~V}_{\mathrm{SCE}}$ to $-1.11 \mathrm{~V}_{\mathrm{SCE}}$. However, petal-like magnetite film containing ferrihydrite and iron was formed at $-1.17 \mathrm{~V}_{\mathrm{SCE}}$. At more negative potential of $-1.23 \mathrm{~V}_{\mathrm{SCE}}$, two distinct layers were observed: a porous outer layer containing ferrihydrite and goethite and a compact inner layer consisting of columnar metallic iron. In the potential range from -1.05 to $-1.11 \mathrm{~V}_{\mathrm{SCE}}$, the pure magnetite films gradually increased the thickness and decreased the surface roughness with an increase of the overpotential. The magnetite film deposited at $-1.11 \mathrm{~V}_{\mathrm{SCE}}$ showed the most thick layer and smooth surface state.
\end{abstract}

\section{Introduction}

Magnetite is one of the principal corrosion products formed on the carbon steel surfaces of piping and equipment of the secondary coolant system in pressurized water reactor (PWR) of nuclear power plant. Magnetite is released from carbon steel surfaces into the high temperature feed water and is transported to the steam generator $[1,2]$. Flow accelerated corrosion (FAC) leads to wall thinning of carbon steel piping and components exposed to flowing water or wet steam in the secondary system of PWR. The process of FAC is related to the dissolution of magnetite on the surface of carbon steel under turbulent flow $[3,4]$. In addition, magnetite deposits on the outside of the steam generator tubes and tube support structure. There has been an intense interest in magnetite deposits on the nuclear materials because its removal improves heat transfer and reduces the corrosion of steam generator tube and other parts of the steam generator system $[5,6]$. In order to evaluate the corrosion behavior of the magnetite covering the nuclear materials, a rigid method to deposit magnetite on the corresponding material substrates should be established. Therefore, it is of high interest to find a simple and efficient method to produce the magnetite film.

Recently, electrodeposition method has extensively been investigated to produce magnetite films [7-12]. There are two basic approaches to deposit the magnetite by anodic deposition in Fe(II) systems [7-10] and cathodic deposition in $\mathrm{Fe}(\mathrm{III})$ systems $[11,12]$. Most of the previous work was conducted in the $\mathrm{Fe}$ (II) systems, where Fe(II) ions were complexed with organic compounds and were electrochemically oxidized to form magnetite film in an inert atmosphere at an elevated temperature. A problem with this method is that the complexed $\mathrm{Fe}$ (II) can be oxidized by molecular oxygen in the air; thus special attention must be paid to exclude molecular oxygen.

Sapieszko and Matijević [13] developed the hydrothermal method to produce the magnetite powder in Fe(III)triethanolamine (TEA) solution agents. Switzer's group have modified the Fe(III)-TEA solution and developed the efficient 
method to produce the magnetite film on the stainless steel substrate [14], single crystal $\mathrm{Au}$ [15], and $\mathrm{Ni}$ [16] at $80^{\circ} \mathrm{C}$. This method is not necessary to eliminate molecular oxygen from the deposition environment due to the good stability of Fe(III)-TEA complex [14-16]. Recently, Switzer's group showed that the polycrystalline magnetite films electrodeposited on stainless steels exhibit multistate resistance switching and resistance switching can be tuned by controlling the composition of the films by varying the deposition potential $[17,18]$. Goujon et al. $[19,20]$ showed the characterization of magnetite films electrodeposited on the Ni-based alloys and established the optimal temperature and agitation condition for electrodeposition to grow magnetite films in the Fe(III)TEA solution. Duan et al. [21] also presented that the concentration of $\mathrm{Fe}$ (III) ions had an impact on the electrodeposition rate, while the deposition temperature and time strongly affected the morphology of the magnetite films.

However, there is a few researches for the electrodeposition of iron-based films on the carbon steel substrate in the Fe(III)-TEA solution. In particular, the effect of deposition potentials on the morphology, structure, thickness, and surface roughness of the electrodeposited films on the carbon steel substrate has not been verified.

The aim of this study is to elucidate the effects of deposition potential on the morphology, structure, thickness, and surface roughness of the electrodeposited films on the carbon steel in Fe(III)-TEA solution, thus establishing the optimal deposition potential to form dense and thick magnetite films. It is considered that these results are useful for simulating the deposited corrosion products on the surface of carbon steel materials in the secondary system of nuclear power plant.

\section{Experimental}

2.1. Material Preparation. Carbon steel specimens for magnetite deposition were machined into $10 \times 5 \times 1 \mathrm{~mm}$ from the SA106Gr.B pipe material. The carbon steel substrates were mechanically ground up to \#1100 grit silicon carbide paper and then ultrasonically cleaned in acetone and deionized water. The chemical composition of SA106Gr.B is given in Table 1.

2.2. Electrodeposition of Films. The iron-based films were electrodeposited from an alkaline solution of $\mathrm{Fe}_{2}\left(\mathrm{SO}_{4}\right)_{3}$ complexed with TEA. The deposition bath for magnetite was prepared by dissolving $26 \mathrm{~g}$ of $\mathrm{Fe}$ (III) sulfate hydrate in $150 \mathrm{~mL}$ of $1 \mathrm{M}$ TEA. It was diluted with $500 \mathrm{~mL}$ of deionized water. The solution was then added to a second solution of $120 \mathrm{~g}$ of $\mathrm{NaOH}$ pellets in $850 \mathrm{~mL}$ of deionized water. The resulting deposition solution was gray-green colored with $\mathrm{pH}$ 12.5 at $25^{\circ} \mathrm{C}$.

The electrochemical deposition was carried out in a three-electrode cell. A saturated calomel electrode (SCE) and a platinum wire were used as the reference and counter electrode, respectively. During the deposition process, the solution was maintained at $80^{\circ} \mathrm{C}$ and stirred at $200 \mathrm{rpm}$. The deposition potentials were as follows: $-1.05 \mathrm{~V}_{\mathrm{SCE}},-1.08 \mathrm{~V}_{\mathrm{SCE}}$, $-1.11 \mathrm{~V}_{\mathrm{SCE}},-1.17 \mathrm{~V}_{\mathrm{SCE}}$, and $-1.23 \mathrm{~V}_{\mathrm{SCE}}$. The electrodeposition time was $1800 \mathrm{~s}$ at all the deposition potentials. To ensure
TABLE 1: Chemical composition of the carbon steel (wt.\%).

\begin{tabular}{lccccccccr}
\hline $\mathrm{C}$ & $\mathrm{Cr}$ & $\mathrm{Ni}$ & $\mathrm{Mo}$ & $\mathrm{Si}$ & $\mathrm{Cu}$ & $\mathrm{Mn}$ & $\mathrm{S}$ & $\mathrm{P}$ & $\mathrm{Fe}$ \\
\hline 0.19 & 0.4 & 0.2 & 0.1 & 0.23 & 0.1 & 1.05 & 0.005 & 0.012 & $\mathrm{Bal}$. \\
\hline
\end{tabular}

a deposition as homogeneous as possible, the carbon steel substrate was fixed in front of the counter electrode. After electrodeposition, the electrodeposited films were carefully rinsed with deionized water and dried in air.

2.3. Characterization of Electrodeposited Films. The electrodeposited films were analyzed by scanning electron microscope-energy dispersive X-ray spectroscopy (SEMEDS) and X-ray diffraction (XRD). In order to analyze the morphology, thickness, and chemical composition of the electrodeposited films on the carbon steel substrate, the electrodeposited films were milled by a focused ion beam (FIB) toward a vertical direction of the electrodeposited films. Adherence of electrodeposited films was confirmed by FIBSEM. The values of the surface roughness were measured using a noncontacting surface profiler. In this paper, the root mean square roughness $\left(R_{q}\right)$ is used. The thickness and roughness of electrodeposited films were measured at least three times to confirm the reproducibility. The values were presented by the average with error bars, and good reproducibility was confirmed.

The chemical species of the electrodeposited films were analyzed using X-ray photoelectron spectroscopy (XPS). An XPS analysis was carried out using a Thermo Fisher Scientific (Theta Probe AR-XPS) X-ray photoelectron spectrometer with an $\mathrm{Al} \mathrm{K} \alpha \mathrm{X}$-ray source $(1486.6 \mathrm{eV})$ operated at $15 \mathrm{kV}$ and $150 \mathrm{~W}$ under a base pressure of $2.7 \times 10^{-7} \mathrm{~Pa}$. The binding energies of all peaks were corrected by the reference $C$ s peak at $284.5 \mathrm{eV}$.

\section{Results and Discussion}

3.1. Electrodeposition of the Films. Figure 1 shows linear sweep voltammogram of the carbon steel substrate in the Fe(III)TEA bath at $80^{\circ} \mathrm{C}$. The potential was swept from the open circuit potential to $-1.30 \mathrm{~V}_{\mathrm{SCE}}$ at a scan rate of $10 \mathrm{mV} / \mathrm{s}$. The electrochemical reduction of $\mathrm{Fe}$ (III)-TEA started at potentials more negative than $-0.95 \mathrm{~V}_{\mathrm{SCE}}$. The first reduction wave of this linear sweep was measured approximately between -0.95 and $-1.20 \mathrm{~V}_{\mathrm{SCE}}$. The second reduction wave was also observed in the potential range from -1.20 to $-1.30 \mathrm{~V}_{\mathrm{SCE}}$.

The electrodeposition of magnetite film in Fe(III)-TEA solution can be simplified by two steps. The first step is that the Fe(III)-TEA solution is electrochemically reduced to an Fe(II)-TEA complex. The reaction, which may occur, is expressed as reaction (1). The second step is that Fe(III)TEA complex would then chemically react with Fe(II)-TEA to produce magnetite at the surface of the substrate in the following reaction (2). The overall electrochemical reaction leading to the formation of magnetite deposit on the substrate 


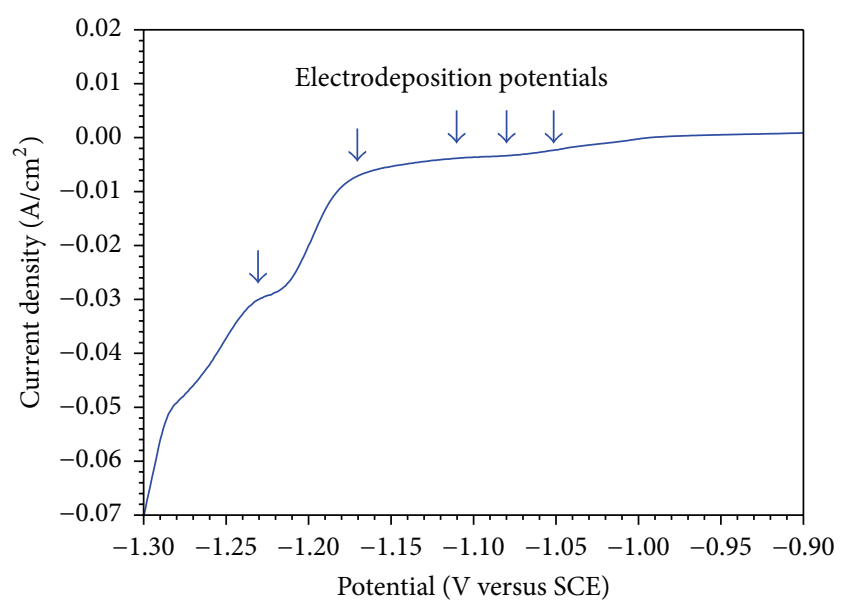

FIGURE 1: Linear sweep voltammogram of the carbon steel substrate in $\mathrm{Fe}(\mathrm{III})$-TEA solution at $80^{\circ} \mathrm{C}$.

is reaction (3). The proposed mechanism is expressed in the following reactions (1) to (3) [14-18]:

$$
\begin{aligned}
& \mathrm{Fe}(\mathrm{OH})_{4} \mathrm{TEA}_{2}{ }^{-}+\mathrm{e}^{-} \longrightarrow \mathrm{Fe}(\mathrm{TEA})_{2}{ }^{2+}+4 \mathrm{OH}^{-} \\
& 2 \mathrm{Fe}(\mathrm{OH})_{4} \mathrm{TEA}_{2}{ }^{-}+\mathrm{Fe}(\mathrm{TEA})_{2}{ }^{2+} \\
& \longleftrightarrow \mathrm{Fe}_{3} \mathrm{O}_{4}+6 \mathrm{TEA}+4 \mathrm{H}_{2} \mathrm{O} \\
& 3 \mathrm{Fe}(\mathrm{OH})_{4} \mathrm{TEA}_{2}{ }^{-}+\mathrm{e}^{-} \\
& \longrightarrow \mathrm{Fe}_{3} \mathrm{O}_{4}+6 \mathrm{TEA}+4 \mathrm{H}_{2} \mathrm{O}+4 \mathrm{OH}^{-}
\end{aligned}
$$

Therefore, the first reduction wave observed between -0.95 and $-1.20 \mathrm{~V}_{\mathrm{SCE}}$ can be attributed to a one electron reaction corresponding to the above reaction (1) $[14,17]$. On the contrary, the second reduction wave between -1.20 and $-1.30 \mathrm{~V}_{\mathrm{SCE}}$ seems to be due to a two-electron process corresponding to the reduction of Fe(II) to Fe [15-18].

Figure 2 shows the surface morphologies of the films formed at different deposition potentials. It is obvious that the morphology depends on the electrochemical potential. The films deposited at -1.05 and $-1.08 \mathrm{~V}_{\mathrm{SCE}}$ have highly faceted morphologies (Figures 2(a) and 2(b)). In this range of potentials, the degree of faceting and particle size of the deposits decrease as the overpotential increases, whereas the film formed at $-1.11 \mathrm{~V}_{\mathrm{SCE}}$ is flat morphologies (Figure 2(c)). As shown in Figure 2(d), the film deposited at $-1.17 \mathrm{~V}_{\mathrm{SCE}}$ has a petal-like microstructure. The film deposited at $-1.23 \mathrm{~V}_{\mathrm{SCE}}$ is similar to that deposited at $-1.17 \mathrm{~V}_{\mathrm{SCE}}$ (Figure $2(\mathrm{e})$ ). These morphologies of the five films are homogeneous on the whole surface of the deposits.

At low overpotentials $(-1.05,-1.08$, and -1.11$)$, the surface concentration of Fe(III) is nearly the same as the bulk concentration because the ion diffusion is sufficient. Hence, the structure is determined by the preferential growth of favorably oriented crystal faces. As a result, the deposited film formed transforms to a dense and crack-free morphology with tightly packed, well-faceted crystallites. Whereas at high overpotentials $\left(-1.17,-1.23 \mathrm{~V}_{\mathrm{SCE}}\right)$ the current becomes masstransport controlled, the surface concentration of Fe(III) approaches zero because the ion diffusion is insufficient. As a result, the resultant structure is dominated by open boundaries and the deposit exhibits a petal-like structure.

Figure 3 shows the FIB-SEM images on a cross section of the electrodeposited films. The films deposited in a range from -1.05 to $-1.11 \mathrm{~V}_{\mathrm{SCE}}$ grew with a columnar morphology. The columns are very compact and adherent to the carbon steel substrate. No defects such as hole, gap, and crack can also be observed at the interface between the deposited films and carbon steel substrate, which confirms that the deposited films are tightly bonded to carbon steel substrate. However, the film deposited at $-1.17 \mathrm{~V}_{\mathrm{SCE}}$ shows a very defective structure containing numerous holes and gaps, indicating that the deposited films are bonded weakly to the carbon steel substrate. The film deposited at $-1.23 \mathrm{~V}_{\mathrm{SCE}}$ consists of two distinct layers: a porous external layer and a compact columnar inner layer. The numerous defects are observed in the external layer, similar to the film at $-1.17 \mathrm{~V}_{\mathrm{SCE}}$. However, no defects such as hole and gap can be observed in the columns and at the interface between the inner layer and carbon steel substrate. The porous cross-sectional structure of the films formed at $-1.17 \mathrm{~V}_{\mathrm{SCE}}$ and $-1.23 \mathrm{~V}_{\mathrm{SCE}}$ is well consistent with the top view images shown in Figures 2(d) and $2(\mathrm{e})$.

Additional analysis was performed to evaluate the double layer observed from the film deposited at $-1.23 \mathrm{~V}_{\mathrm{SCE}}$. Figure 4 shows the EDS element profile. Only iron without oxygen was detected in the inner columnar layer and the content of iron gradually increased as departing from the interface. It is therefore believed that the inner layer is composed of pure metallic iron.

\subsection{Characterization of the Deposited Films. Figure 5 shows} the XRD patterns of the deposited films at the various deposition potentials. In the range from -1.05 to $-1.11 \mathrm{~V}_{\mathrm{SCE}}$, the XRD pattern shows that deposited films are all crystalline and only have peaks corresponding to magnetite. The very weak iron peak from the film at $-1.08 \mathrm{~V}_{\mathrm{SCE}}$ is probably originated from the carbon steel substrate. The intensity of magnetite diffraction peaks is almost equivalent. At the electrodeposition potential of $-1.17 \mathrm{~V}_{\mathrm{SCE}}$, new XRD peaks corresponding to ferrihydrite and iron appeared, indicating the formation of a mixture of three structures: magnetite, ferrihydrite, and iron. When the electrodeposition potential has been moved to $-1.23 \mathrm{~V}_{\mathrm{SCE}}$, additional $\mathrm{XRD}$ peak was detected and indexed to goethite. It should be noted that the peak intensity of iron became higher than that of magnetite. Consequently, this film consisted of a mixture of complex phases: magnetite, ferrihydrite, goethite, and iron. The above XRD results indicate that the deposition potential strongly affects not only the morphology but also the structure of the deposited films.

The detection of metallic iron is in good agreement with the observation of the inner column layer consisting of metallic iron shown in Figure 4. Ferrihydrite was also detected by Mossbauer spectroscopy and XRD on the films deposited in the same electrochemical solution $[15,19]$. However, goethite and metallic iron were not reported. Since the driving force for reduction became larger at more negative 


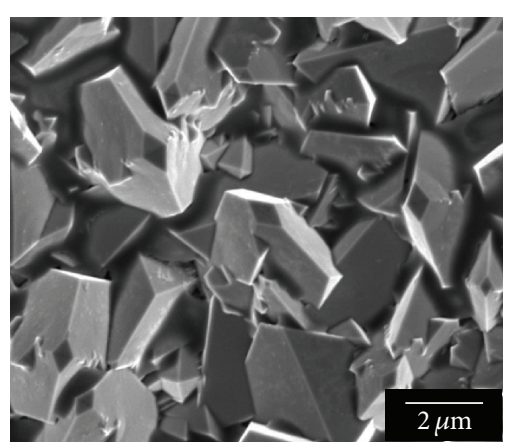

(a)

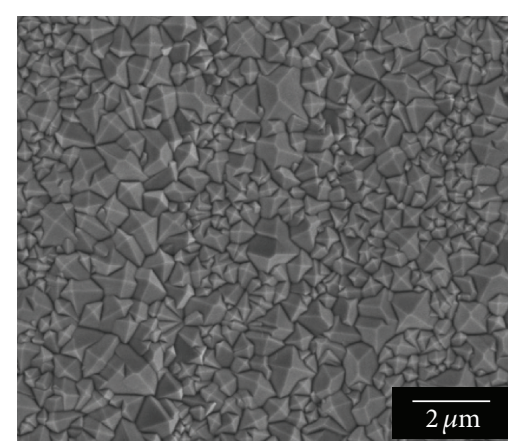

(b)

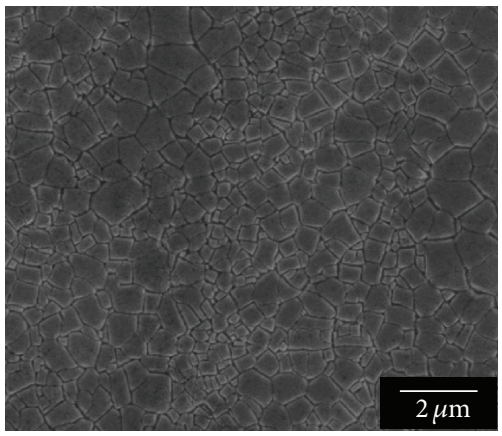

(c)

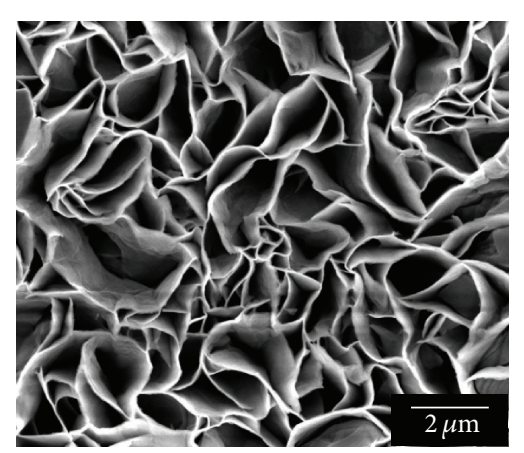

(d)

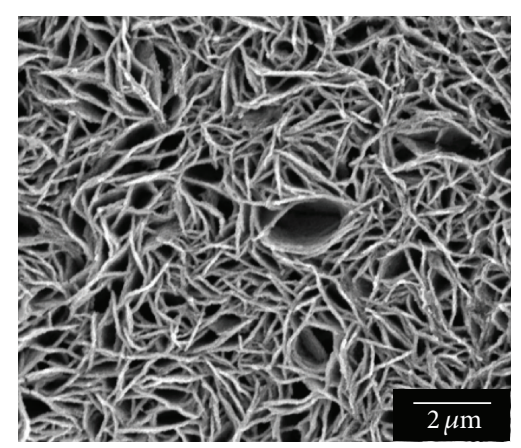

(e)

FIgURE 2: SEM surface images of electrodeposited films on the carbon steel substrate at the various deposition potentials in Fe(III)-TEA solution for $1800 \mathrm{~s}$ at $80^{\circ} \mathrm{C}$ : (a) -1.05 , (b) -1.08 , (c) -1.11 , (d) -1.17 , and (e) $-1.23 \mathrm{~V}_{\mathrm{SCE}}$.

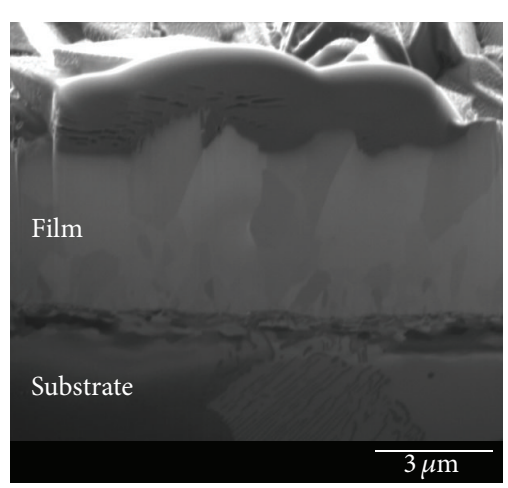

(a)

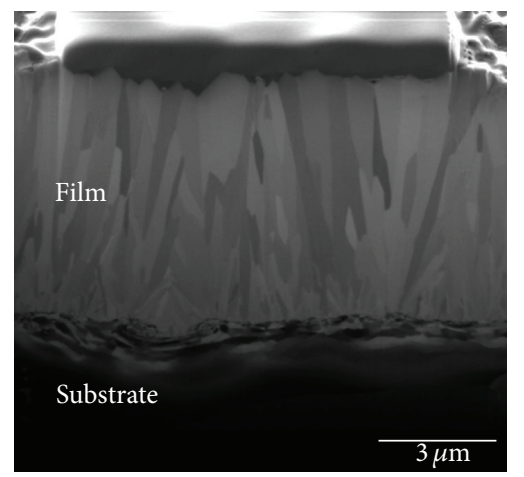

(b)

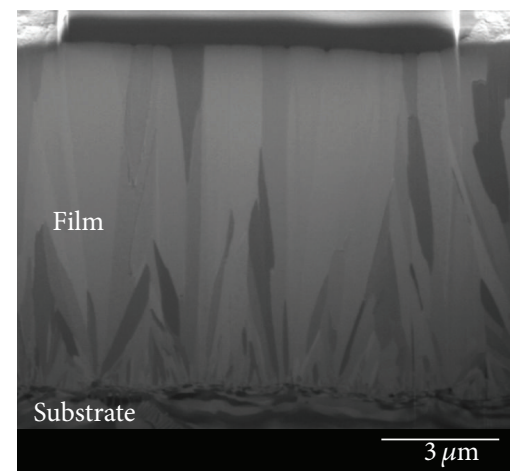

(c)

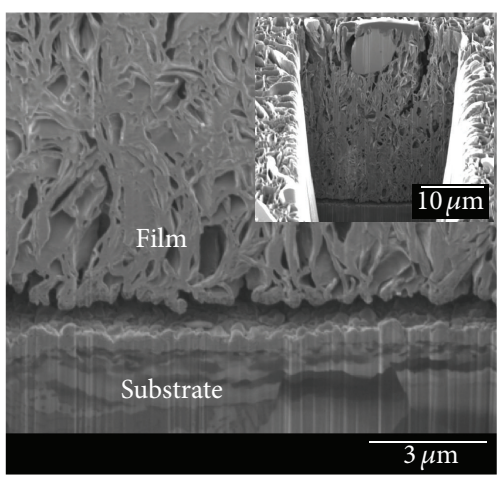

(d)

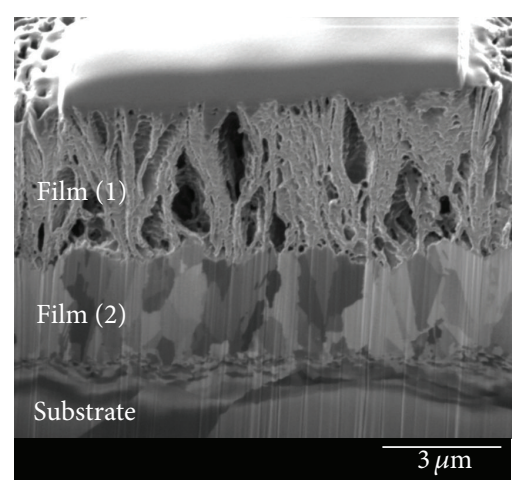

(e)

FIGURE 3: FIB-SEM images of the cross section of the electrodeposited films on the carbon steel substrate at the various deposition potentials in $\mathrm{Fe}$ (III)-TEA solution for $1800 \mathrm{~s}$ at $80^{\circ} \mathrm{C}$ : (a) -1.05 , (b) -1.08 , (c) -1.11 , (d) -1.17 , and (e) $-1.23 \mathrm{~V}_{\mathrm{SCE}}$. 


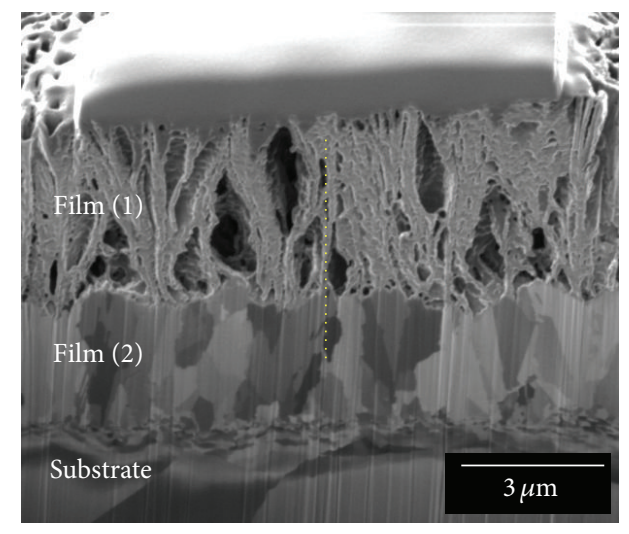

(a)

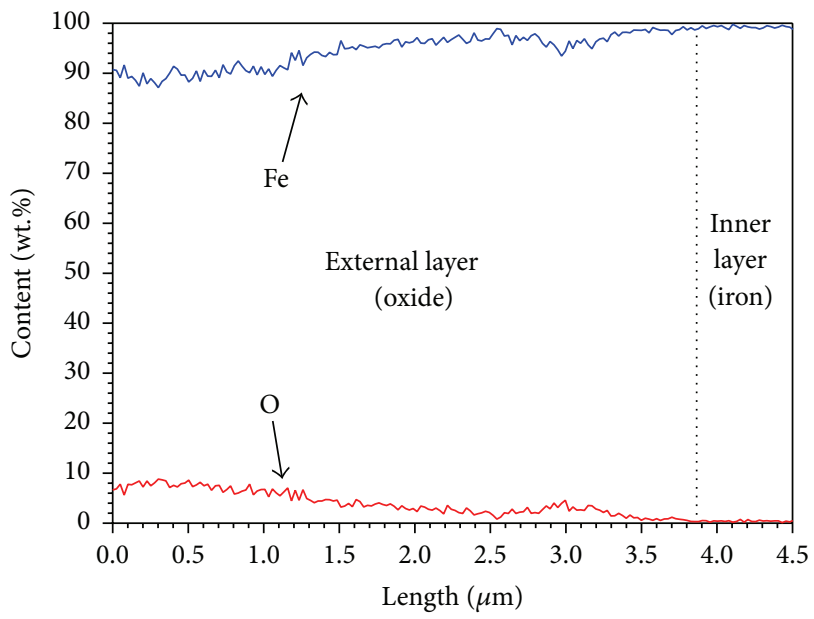

(b)

FIGURE 4: Cross-sectional EDS analysis of the film electrodeposited at $-1.23 \mathrm{~V}_{\mathrm{SCE}}$ on the carbon steel substrate in Fe(III)-TEA solution for $1800 \mathrm{~s}$ at $80^{\circ} \mathrm{C}$ : (a) SEM image and (b) line analysis.

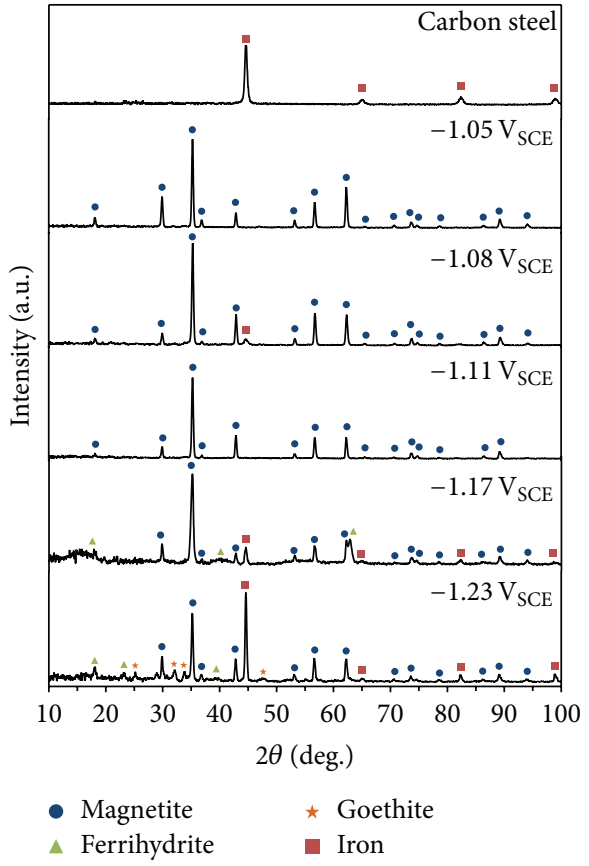

FIGURE 5: XRD analysis of the electrodeposited films on the carbon steel substrate at the various deposition potentials in Fe(III)-TEA solution for $1800 \mathrm{~s}$ at $80^{\circ} \mathrm{C}$.

potential, $\mathrm{Fe}$ (III) in the solution can be reduced to metallic iron. In addition to the reduction force, the mass transfer rate of $\mathrm{Fe}(\mathrm{II})$ in the solution to the substrate will be fast at more negative potential. This will increase the deposition rate of magnetite through reactions (1) and (2). Consequently, the presence of ferrihydrite and goethite is unexpected at a lower electrochemical potential. Although the formation of ferrihydrite can be attributed to the aerial oxidation of a film in basic conditions [15], further study is needed.
Figure 6 shows Fe 2p and O 1s XPS spectra of the films deposited at the various potentials. As shown in Figure 6(a), Fe $2 p$ core levels were split into $2 p_{3 / 2}$ and $2 p_{1 / 2}$ doublet. The binding energy of Fe $2 \mathrm{p}_{3 / 2}$ and Fe $2 \mathrm{p}_{1 / 2}$ of the film deposited at $-1.05 \mathrm{~V}_{\mathrm{SCE}}$ was 710.8 and $724.0 \mathrm{eV}$, respectively, which is in good agreement with the reported values for $\mathrm{Fe}_{3} \mathrm{O}_{4}[22,23]$. However, the peak positions for $\mathrm{Fe} 2 \mathrm{p}_{1 / 2}$ and $\mathrm{Fe} 2 \mathrm{p}_{3 / 2}$ slightly shifted to the higher binding energy side with an increase of the overpotential. This indicates an increase in the proportion of Fe(III) species in the films. The binding energy of ferrihydrite and goethite is higher than that of pure magnetite $[24,25]$. Therefore, the shift of the peak positions to the higher binding energy is attributed to the formation of ferrihydrite and goethite. The binding energies of $\mathrm{O} 1 \mathrm{~s}$ are found at $530.0 \mathrm{eV}$ corresponding to $\mathrm{O}^{2-}$ bonds and at $531.1 \mathrm{eV}$ corresponding to $\mathrm{OH}^{-}$bonds (Figure 6(b)). In the $\mathrm{O} 1 \mathrm{~s}$ spectrum, the film deposited at $-1.23 \mathrm{~V}_{\mathrm{SCE}}$ has its maximum at $531.1 \mathrm{eV}$ due to $\mathrm{OH}^{-}$bonds.

This is well consistent with the XRD analysis shown in Figure 4 . It should be noted that the above Fe $2 p$ spectra represent the chemical states of the outermost surface film, because the spectra were obtained without sputtering. Therefore, the above XPS results do not entirely reflect the XRD analysis.

Figure 7 shows the thickness variation of the deposited films with the deposition potentials. The thickness of the deposited films gradually increased with an increase of the overpotential in the range from -1.05 to $-1.17 \mathrm{~V}_{\mathrm{SCE}}$, whereas the thickness sharply decreased at $-1.23 \mathrm{~V}_{\mathrm{SCE}}$. The largest thickness of the deposited film at $-1.17 \mathrm{~V}_{\mathrm{SCE}}$ was about $33.2 \mu \mathrm{m}$. The double layered films at $-1.23 \mathrm{~V}_{\mathrm{SCE}}$ consisted of about $4.6 \mu \mathrm{m}$ of the porous external film and about $4.6 \mu \mathrm{m}$ of the compact inner film for a total of about $8.1 \mu \mathrm{m}$.

Figure 8 shows the variation of deposition current density at each potential during the deposition. It is clear that the more negative deposition potential is, the higher current density is, resulting in a thick film. In particular, the abrupt 


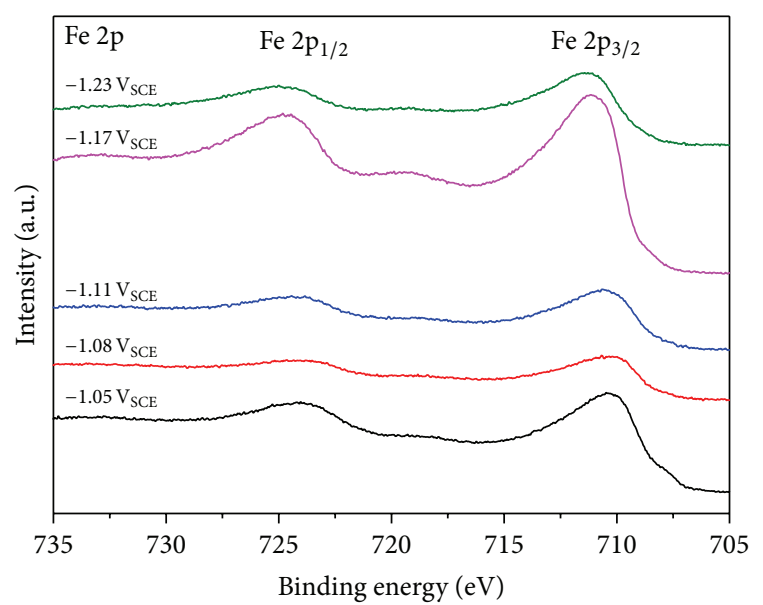

(a)

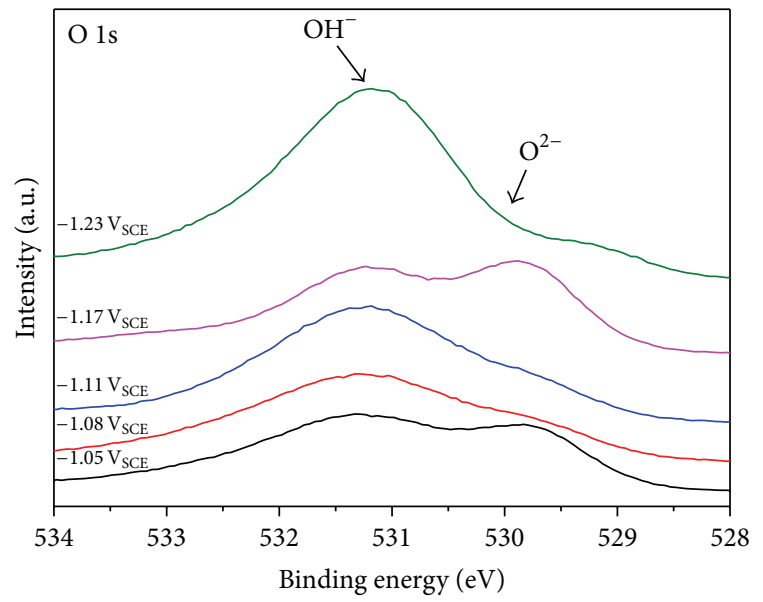

(b)

FIGURE 6: XPS spectra of the electrodeposited films on the carbon steel substrate at the various potentials in $\mathrm{Fe}$ (III)-TEA solution for $1800 \mathrm{~s}$ at $80^{\circ} \mathrm{C}$ : (a) Fe $2 \mathrm{p}$ and (b) $\mathrm{O} 1 \mathrm{~s}$.

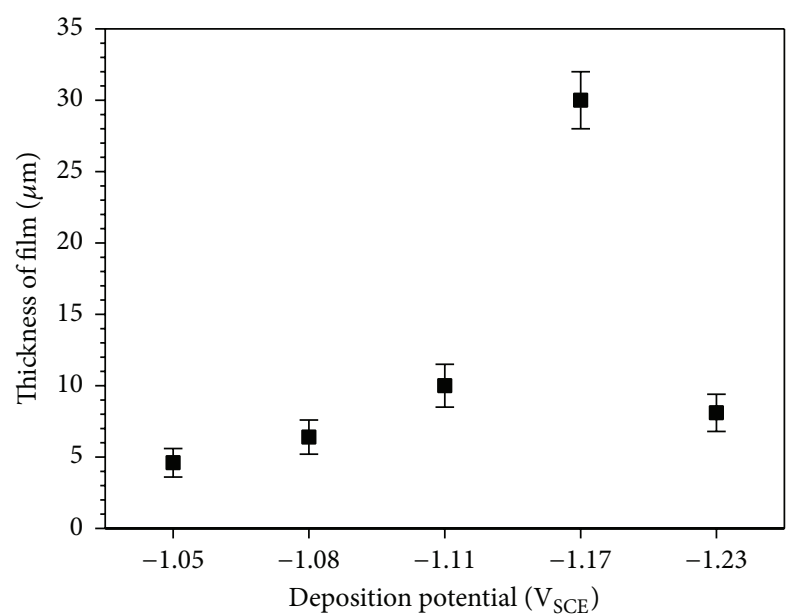

FIgURE 7: Thickness of the electrodeposited films on the carbon steel substrate at the various deposition potentials in Fe(III)-TEA solution for $1800 \mathrm{~s}$ at $80^{\circ} \mathrm{C}$.

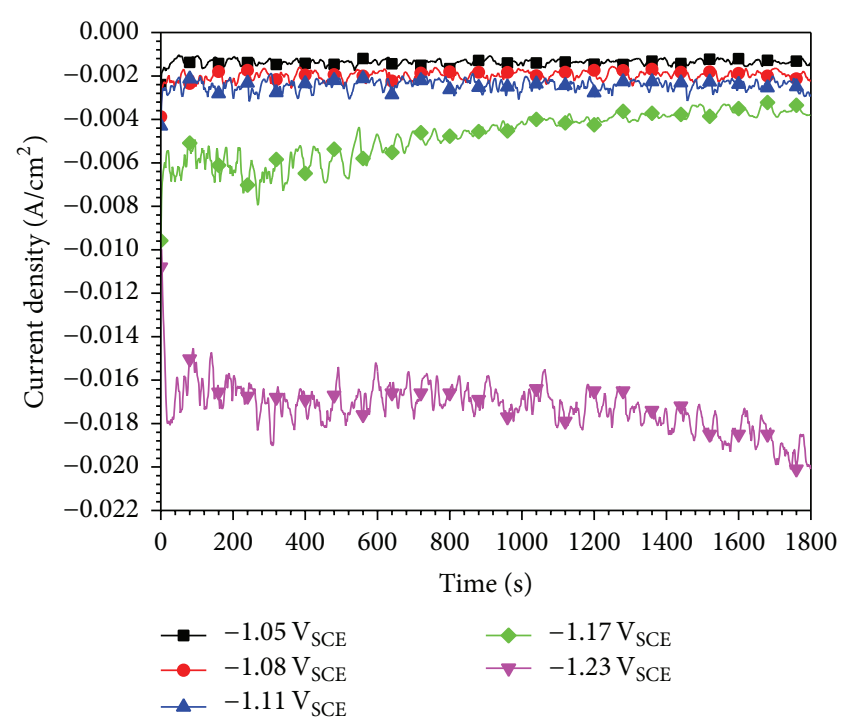

FIGURE 8: Current density variation at different potentials during electrochemical deposition in Fe(III)-TEA solution for $1800 \mathrm{~s}$ at $80^{\circ} \mathrm{C}$.

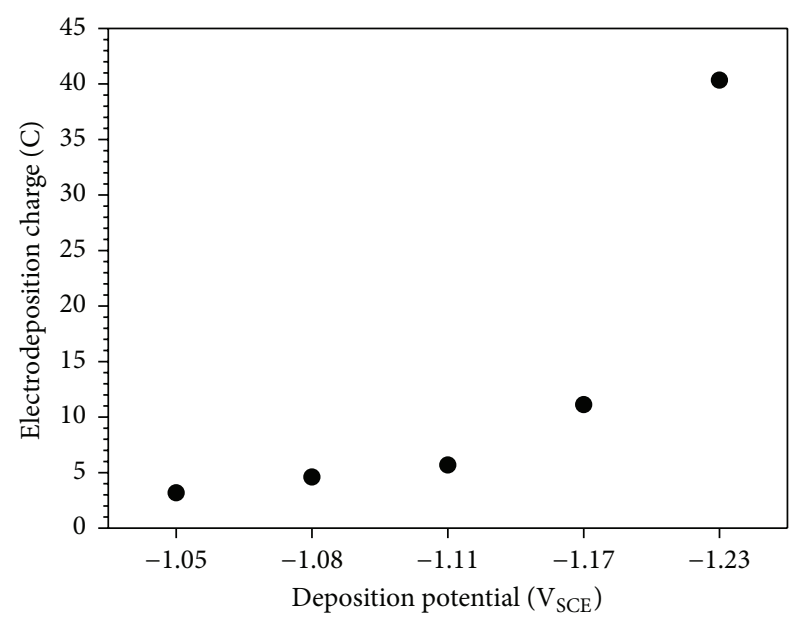

FIgURE 9: Electrodeposition charge at different potentials during electrochemical deposition in Fe(III)-TEA solution for $1800 \mathrm{~s}$ at $80^{\circ} \mathrm{C}$.

increase of the film at $-1.17 \mathrm{~V}_{\mathrm{SCE}}$ can be attributed to 2dimensional growth perpendiculars to the substrate and the resulting porous structure as shown in Figures 2(d) and 3(d). Comparing the thickness of the films, the film deposited at $-1.23 \mathrm{~V}_{\mathrm{SCE}}$ is thinner than that deposited at $-1.11 \mathrm{~V}_{\mathrm{SCE}}$, although the current density at $-1.23 \mathrm{~V}_{\mathrm{SCE}}$ is about three times higher than that at $-1.11 \mathrm{~V}_{\mathrm{SCE}}$. This is because the three electrons are consumed to reduce Fe(III) ion to a metallic ion.

Figure 9 shows the electrodeposition charge was measured at the various potentials during electrochemical deposition. Total amount of electric charge was increased with increasing deposition potential in negative direction.

Figure 10 shows the surface roughness of films on the carbon steel substrate deposited at the various potentials using a noncontacting surface profiler. The roughness variation of 

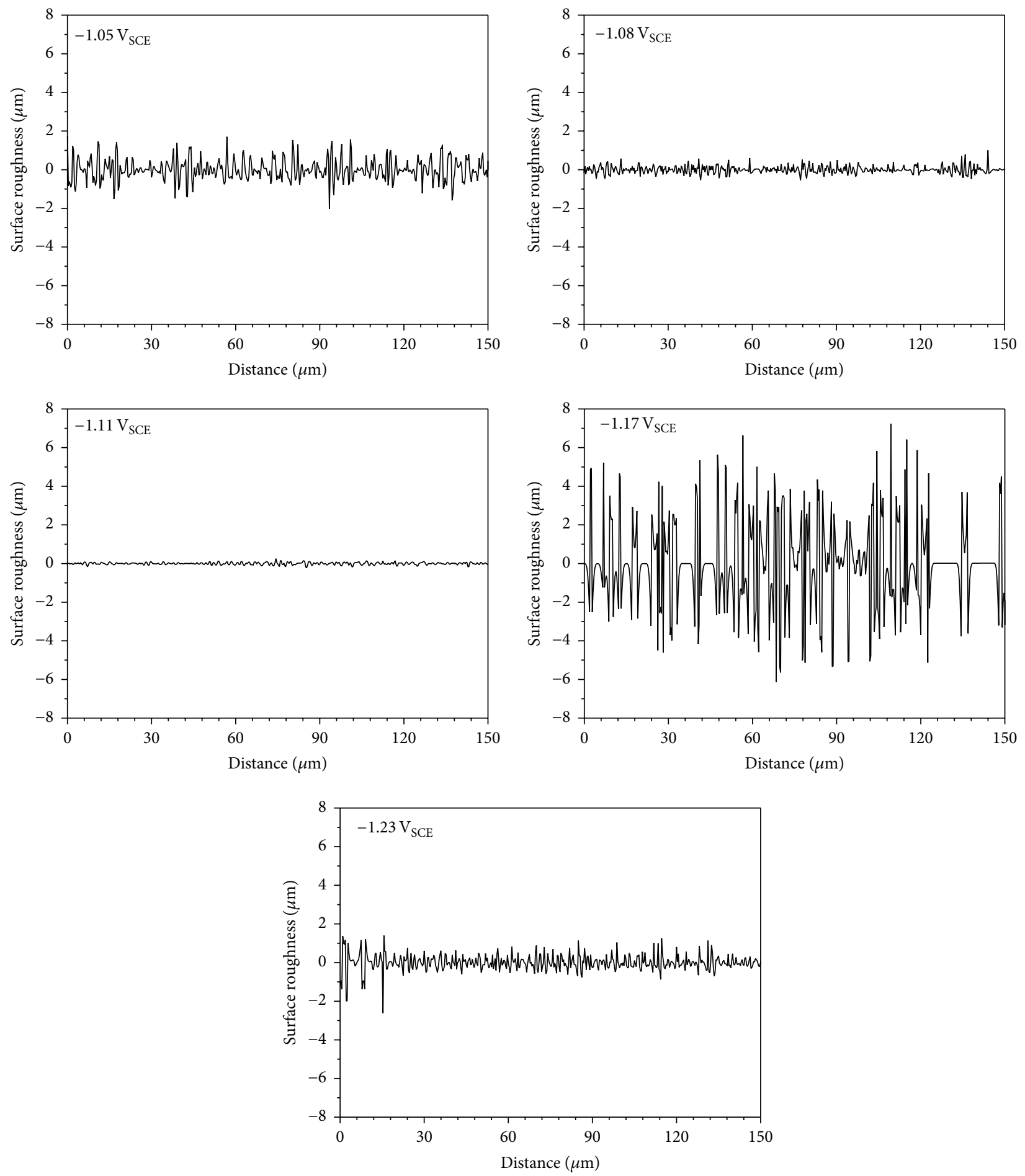

FIGURE 10: Surface roughness profile of electrodeposited films on the carbon steel substrate at the various deposition potentials in the Fe(III)TEA solution for $1800 \mathrm{~s}$ at $80^{\circ} \mathrm{C}$.

films is well associated with the surface morphology of the films shown in Figure 2. The roughness of the deposited films gradually decreased with an increase of the overpotential in the range from -1.05 to $-1.11 \mathrm{~V}_{\mathrm{SCE}}$ due to the decrease of particle size. The steep increase in the roughness at $-1.17 \mathrm{~V}_{\mathrm{SCE}}$ is owing to the porous petal-like morphology. At the deposition potential of $-1.23 \mathrm{~V}_{\mathrm{SCE}}$, the roughness decreased in accordance with the more dense surface morphology of the film. As shown in Figure 11, the value of $R_{q}$ of the deposited films on the carbon steel substrate is obtained from the 


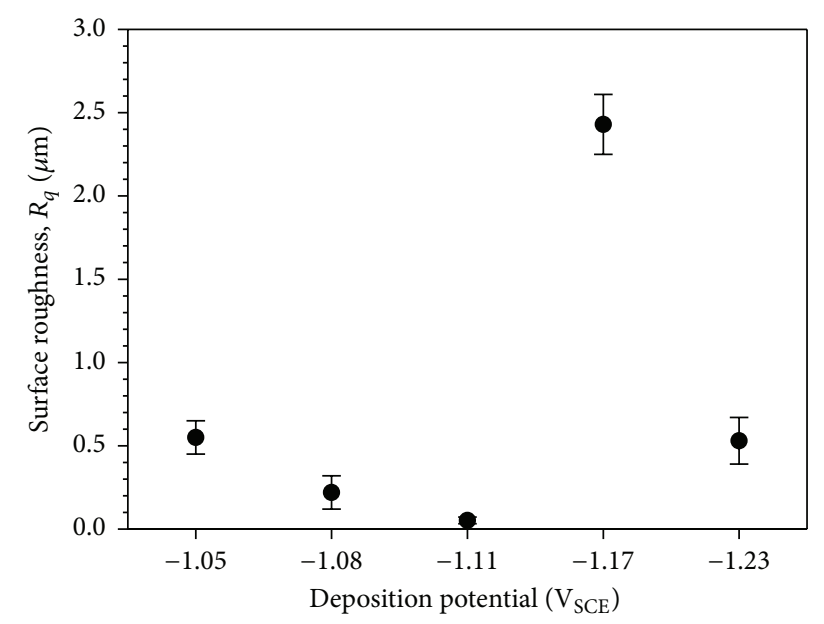

FIGURE 11: Surface roughness of the electrodeposited films on the carbon steel substrate at the various deposition potentials in $\mathrm{Fe}(\mathrm{III})$ TEA solution for $1800 \mathrm{~s}$ at $80^{\circ} \mathrm{C}$.

surface roughness curve. The surface roughness value of the deposited films at $-1.11 \mathrm{~V}_{\mathrm{SCE}}$ was the smallest with $0.06 \mu \mathrm{m}$.

Based on the results obtained in this work, it is confirmed that the electrochemical potentials affect the morphology, structure, thickness, and surface roughness of the deposited films.

In actual secondary system of nuclear power plants, porous magnetite is the main corrosion product formed on the surface of carbon steel piping, steam generator tubing, and other support structures due to the alkaline and reducing condition. Though the corrosion products are mainly made of magnetite, other corrosion products such as ferrihydrite and goethite are also present [26]. And thickness of real corrosion products on carbon steel piping, steam generator tubing, and other support structures exceeds several tens of micrometers. The film deposited at $-1.17 \mathrm{~V}_{\mathrm{SCE}}$ has porous morphology and several tens of micrometers thickness. Furthermore, this film contains the magnetite and ferrihydrite like the actual corrosion products in secondary system of nuclear power plants. Based on these results, the deposition potential at $-1.17 \mathrm{~V}_{\mathrm{SCE}}$ is appropriate to simulate the real corrosion products formed in the secondary system of nuclear power plants. However, the deposition potential range from $-1.05 \mathrm{~V}_{\mathrm{SCE}}$ to $-1.11 \mathrm{~V}_{\mathrm{SCE}}$ is proper deposition condition to use specimens for the electrochemical tests due to the formation of pure adhesive homogeneous magnetite. In this range, the film deposited at $-1.11 \mathrm{~V}_{\mathrm{SCE}}$ showed the most thick layer and smooth surface state. Therefore, the optimal potential for the electrodeposition of pure magnetite on the carbon steel substrate was determined to be $-1.11 \mathrm{~V}_{\mathrm{SCE}}$.

To simulate the electrochemical corrosion behavior of the magnetite covering the materials, a rigid method to deposit magnetite on the corresponding material substrates should be established. In this respect, it is considered that these results are useful for simulating the deposited magnetite on the surface of carbon steel materials in the secondary system.

\section{Conclusions}

Magnetite films were electrodeposited on carbon steel substrate at different potentials in $\mathrm{Fe}(\mathrm{III})-\mathrm{TEA}$ solution at $80^{\circ} \mathrm{C}$. The electrochemical potentials affected the morphology, structure, thickness, and surface roughness of the deposited films. Pure magnetite films with a compact and defect-free structure were electrodeposited in the potential range from $-1.05 \mathrm{~V}_{\mathrm{SCE}}$ to $-1.11 \mathrm{~V}_{\mathrm{SCE}}$. Porous magnetite film containing ferrihydrite and iron was obtained at $-1.17 \mathrm{~V}_{\mathrm{SCE}}$. At a more negative potential at $-1.23 \mathrm{~V}_{\mathrm{SCE}}$, double layered film was formed: a porous outer layer containing ferrihydrite and goethite and an inner columnar layer consisting of metallic iron. Based on these results, the optimal potential for the electrodeposition of pure magnetite was determined to be $-1.11 \mathrm{~V}_{\mathrm{SCE}}$. These results are useful to prepare magnetite specimens for the electrochemical corrosion tests of magnetite itself and materials in contact with magnetite.

\section{Conflict of Interests}

The authors declare that there is no conflict of interests regarding the publication of this paper.

\section{Acknowledgment}

This work was supported by the National Research Foundation of Korea (NRF) grant funded by the Korean government (MSIP).

\section{References}

[1] C. Ramesh, N. Murugesan, A. A. M. Prince, S. Velmurugan, S. V. Narasimhan, and V. Ganesan, "Application of polymer electrolyte based hydrogen sensor to study corrosion of carbon steel in acid medium," Corrosion Science, vol. 43, no. 10, pp. 1865-1875, 2001.

[2] A. A. M. Prince, S. Velmurugan, S. V. Narasimhan et al., "Dissolution behaviour of magnetite film formed over carbon steel in dilute organic acid media," Journal of Nuclear Materials, vol. 289, no. 3, pp. 281-290, 2001.

[3] C. Hales, K. J. Stevens, P. L. Daniel, M. Zamanzadeh, and A. D. Owens, "Boiler feedwater pipe failure by flow-assisted chelant corrosion," Engineering Failure Analysis, vol. 9, no. 2, pp. 235243, 2002.

[4] X. Jiang, Y. G. Zheng, and W. Ke, "Effect of flow velocity and entrained sand on inhibition performances of two inhibitors for $\mathrm{CO}_{2}$ corrosion of $\mathrm{N} 80$ steel in $3 \% \mathrm{NaCl}$ solution," Corrosion Science, vol. 47, no. 11, pp. 2636-2658, 2005.

[5] S. Odar, "Water chemistry measures to improve steam generator performance," in Proceedings of the 14th International Conference on the properties of Water and Steam, pp. 531-538, Kyoto, Japan, August 2004.

[6] D. H. Hur, M. S. Choi, U. C. Kim, and J. H. Han, "Magnetite dissolution and corrosion behavior in high temperature EDTA solvents," Nuclear Engineering and Design, vol. 220, no. 1, pp. 1116, 2003.

[7] M. P. Nikiforov, A. A. Vertegel, M. G. Shumsky, and J. A. Switzer, "Epitaxial electrodeposition of $\mathrm{Fe}_{3} \mathrm{O}_{4}$ on single-crystal $\mathrm{Au}(111), "$ Advanced Materials, vol. 12, no. 18, pp. 1351-1353, 2000. 
[8] D. Carlier, C. Terrier, C. Arm, and J.-P. Ansermet, "Preparation and magnetic properties of $\mathrm{Fe}_{3} \mathrm{O}_{4}$ nanostructures grown by electrodeposition," Electrochemical and Solid-State Letters, vol. 8, no. 3, pp. C43-C46, 2005.

[9] S. Peulon, H. Antony, L. Legrand, and A. Chausse, "Thin layers of iron corrosion products electrochemically deposited on inert substrates: synthesis and behaviour," Electrochimica Acta, vol. 49, no. 17-18, pp. 2891-2899, 2004.

[10] S.-Y. Wang, K.-C. Ho, S.-L. Kuo, and N.-L. Wu, "Investigation on capacitance mechanisms of $\mathrm{Fe}_{3} \mathrm{O}_{4}$ electrochemical capacitors," Journal of the Electrochemical Society, vol. 153, no. 1, pp. A75-A80, 2006.

[11] C.-L. Teng and M. P. Ryan, "A morphological study of nanocrystalline magnetite electrodeposited onto polycrystalline copper substrates," Electrochemical and Solid-State Letters, vol. 10, no. 10, pp. D108-D112, 2007.

[12] S. Mitra, P. Poizot, A. Finke, and J.-M. Tarascon, "Growth and electrochemical characterization versus lithium of $\mathrm{Fe}_{3} \mathrm{O}_{4}$ electrodes made by electrodeposition," Advanced Functional Materials, vol. 16, no. 17, pp. 2281-2287, 2006.

[13] R. S. Sapieszko and E. Matijević, "Preparation of well-defined colloidal particles by thermal decomposition of metal chelates. I. Iron oxides," Journal of Colloid And Interface Science, vol. 74, no. 2, pp. 405-422, 1980.

[14] H. M. Kothari, E. A. Kulp, S. J. Limmer, P. Poizot, E. W. Bohannan, and J. A. Switzer, "Electrochemical deposition and characterization of $\mathrm{Fe}_{3} \mathrm{O}_{4}$ films produced by the reduction of Fe(III)-triethanolamine," Journal of Materials Research, vol. 21, no. 1, pp. 293-301, 2006.

[15] E. A. Kulp, H. M. Kothari, S. J. Limmer et al., "Electrodeposition of epitaxial magnetite films and ferrihydrite nanoribbons on single-crystal gold," Chemistry of Materials, vol. 21, no. 21, pp. 5022-5031, 2009.

[16] R. V. Gudavarthy, S. Gorantla, G. Mu et al., "Epitaxial electrodeposition of $\mathrm{Fe}_{3} \mathrm{O}_{4}$ on single-crystal $\mathrm{Ni}(111)$," Chemistry of Materials, vol. 23, no. 8, pp. 2017-2019, 2011.

[17] J. A. Switzer, R. V. Gudavarthy, E. A. Kulp, G. Mu, Z. He, and A. J. Wessel, "Resistance switching in electrodeposited magnetite superlattices," Journal of the American Chemical Society, vol. 132, no. 4, pp. 1258-1260, 2010.

[18] R. V. Gudavarthy, A. S. Miller, E. W. Bohannan, E. A. Kulp, Z. $\mathrm{He}$, and J. A. Switzer, "Resistance switching in electrodeposited polycrystalline $\mathrm{Fe}_{3} \mathrm{O}_{4}$ films," Electrochimica Acta, vol. 56, no. 28, pp. 10550-10556, 2011.

[19] C. Goujon, T. Pauporté, C. Mansour, S. Delaunary, and J. L. Bretelle, "Fouling of steam generator tubes in nuclear power plants: laboratory tests to reproduce oxides deposition," in Proceedings of the International Conference on Heat Exchanger Fouling and Cleaning, pp. 101-107, Budapest, Hungary, June 2013.

[20] C. Goujon, T. Pauporté, C. Mansour, S. Delaunay, and J. Bretelle, "Electrochemical deposition of thick iron oxide films on nickel based superalloy substrates," Electrochimica Acta, vol. 176, pp. 230-239, 2015.

[21] H. Duan, X. Chen, B. Li, and J. Liang, "Growth morphology study of cathodically electrodeposited $\mathrm{Fe}_{3} \mathrm{O}_{4}$ thin films at elevated temperatures," Materials Research Bulletin, vol. 45, no. 11, pp. 1696-1702, 2010.

[22] Y. Jia, X.-Y. Yu, T. Luo, M.-Y. Zhang, J.-H. Liu, and X.-J. Huang, "Two-step self-assembly of iron oxide into three-dimensional hollow magnetic porous microspheres and their toxic ion adsorption mechanism," Dalton Transactions, vol. 42, no. 5, pp. 1921-1928, 2013.
[23] L. Martinez, D. Leinen, F. Martín et al., "Electrochemical growth of diverse iron oxide $\left(\mathrm{Fe}_{3} \mathrm{O}_{4}, \alpha-\mathrm{FeOOH}\right.$, and $\gamma$-FeOOH$)$ thin films by electrodeposition potential tuning," Journal of the Electrochemical Society, vol. 154, no. 3, pp. D126-D133, 2007.

[24] H. Abdel-Samad and P. R. Watson, "An XPS study of the adsorption of lead on goethite $(\alpha-\mathrm{FeOOH})$, , Applied Surface Science, vol. 136, no. 1-2, pp. 46-54, 1998.

[25] P. Ghods, O. B. Isgor, F. Bensebaa, and D. Kingston, "Angleresolved XPS study of carbon steel passivity and chlorideinduced depassivation in simulated concrete pore solution," Corrosion Science, vol. 58, pp. 159-167, 2012.

[26] H. Namduri, Formation and quantification of corrosion deposits in the power industry [Ph.D. dissertation], University of North Texas, Denton, Tex, USA, 2007. 

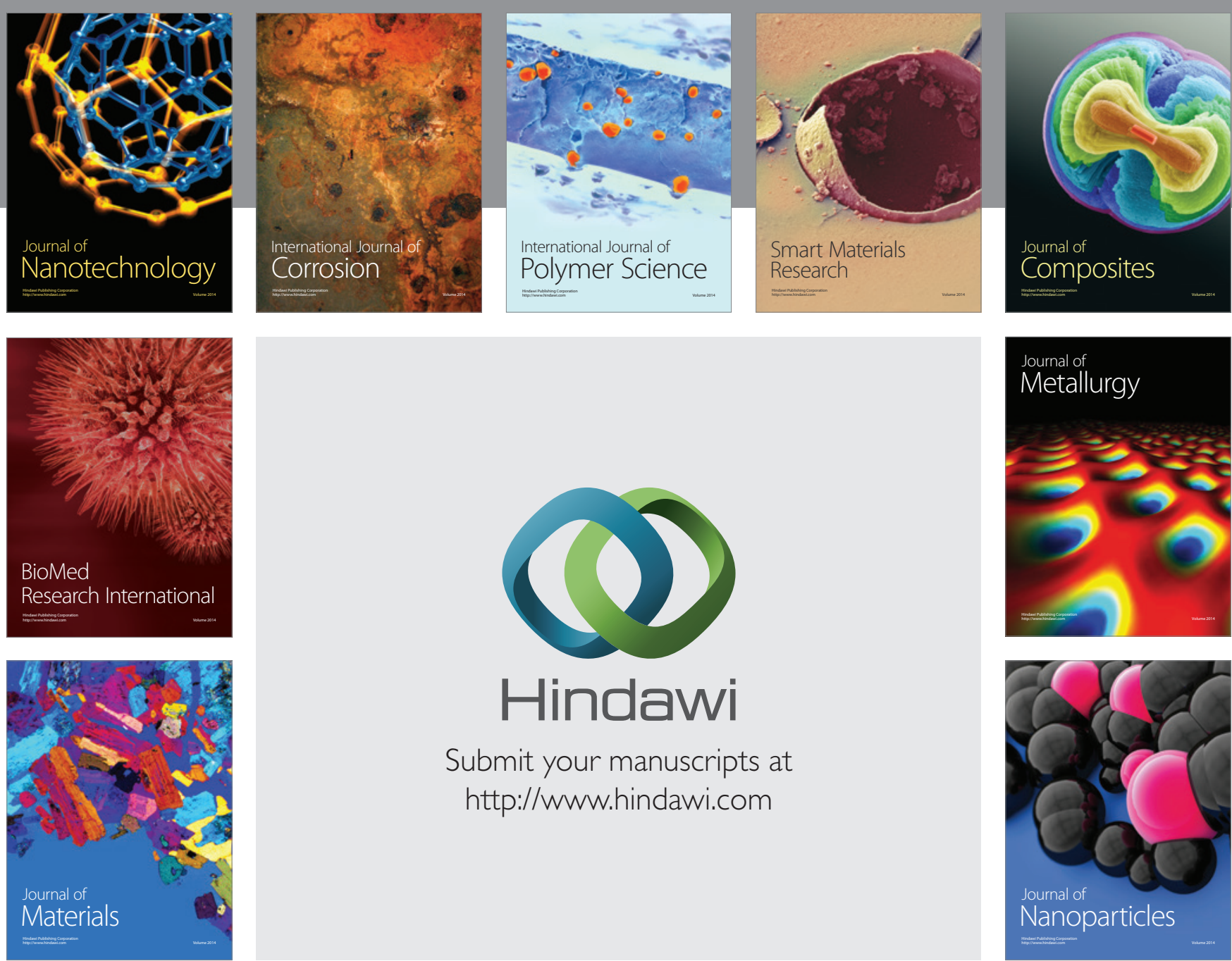

\section{Hindawi}

Submit your manuscripts at

http://www.hindawi.com

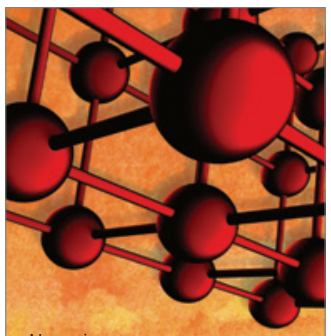

Materials Science and Engineering
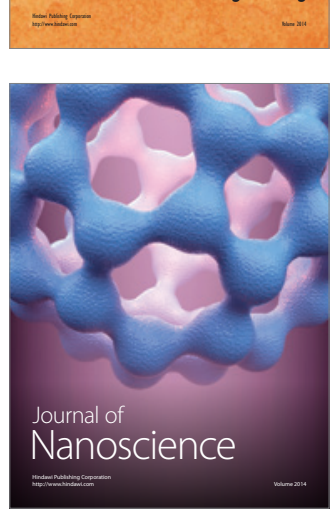
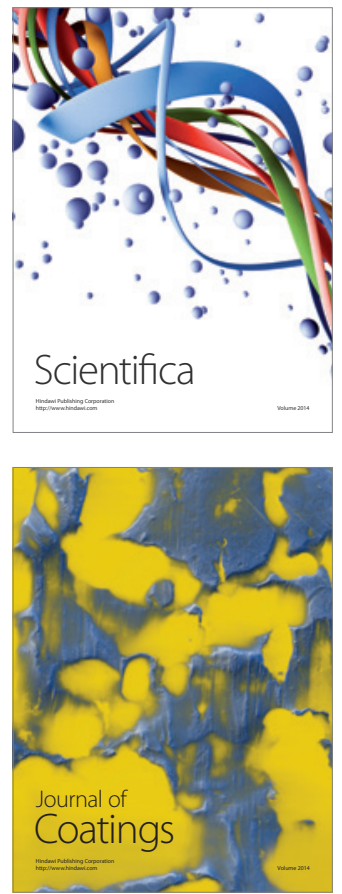
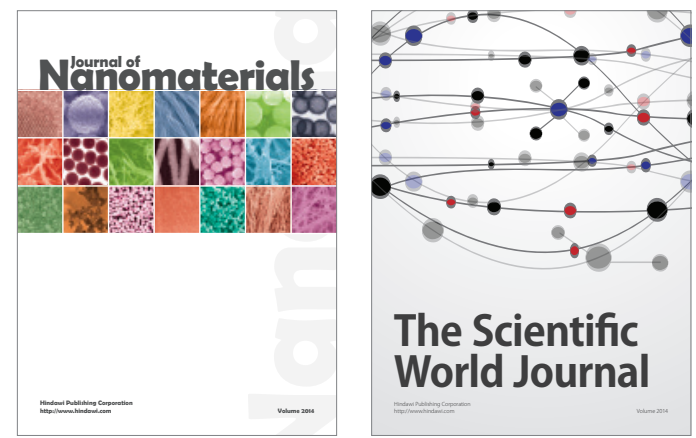

The Scientific World Journal
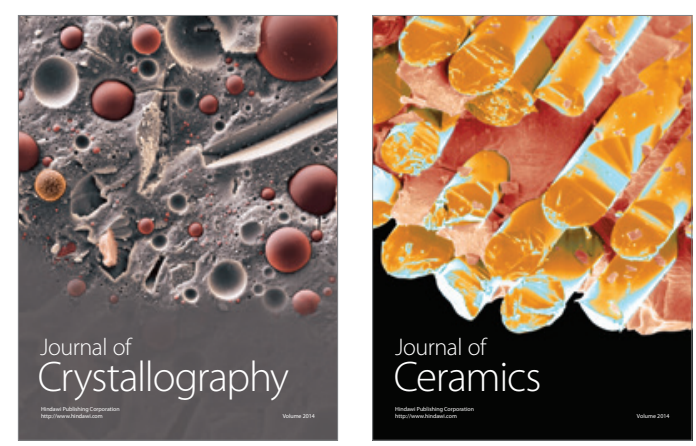
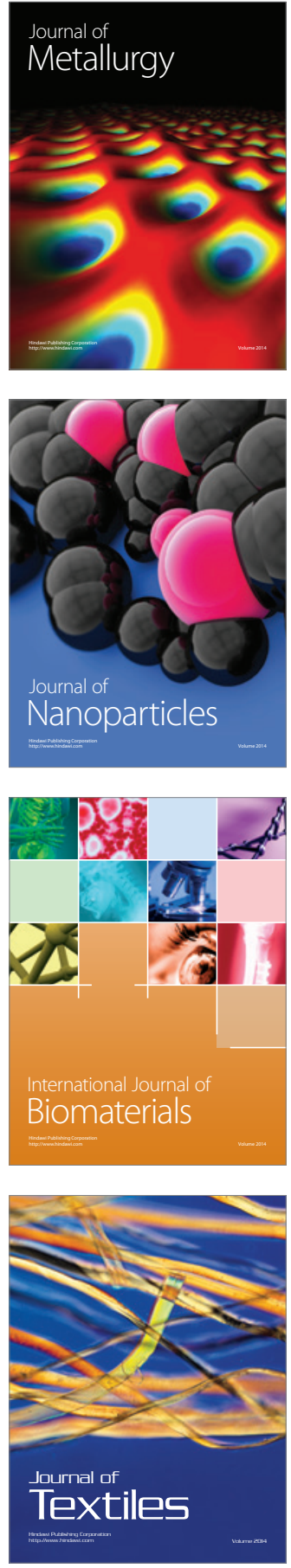